\title{
Migrated Intrauterine Contraceptive Device: Incidental Finding in the Descending Sigmoid Colon
}

\author{
Cipta Pramana ${ }^{1}$, Gede Raditya Yoga ${ }^{2}$, Hosein Ivan Setiabudi ${ }^{2}$ \\ ${ }^{1}$ Department of Obstetrics and Gynecology, K.R.M.T. Wongsonegoro General Hospital Semarang, Indonesia/ Medicine Faculty of \\ Tarumanagara University Jakarta, Indonesia; ${ }^{2}$ Medicine Faculty of Tarumanagara University Jakarta, Indonesia.
}

\section{Corresponding Author:}

Dr. Cipta Pramana

Email: pramanacipta@yahoo.com

This is an Open Access article distributed under the terms of the Creative Commons Attribution License (creativecommons.org) licenses/by/3.0).

Received : March 17, 2020

Accepted : July 3,2020

Published : July 25, 2020

\begin{abstract}
Background: The migration of the intra-uterine device (IUD) to the colon is a rare but can cause serious complications. Removal of migrated IUD is highly recommended considering that it can lead to risks of complications, such as fistula formation and colonic perforation. Case Report: We hereby report 45-year-old woman with IUD implanted in the sigmoid intestine, which was removed by laparotomy and laparoscopy. Conclusion: The migration of IUD must be treated even in asymptomatic patients due to the risk of severe complications.
\end{abstract}

Keywords: Colonic Diseases, Fistula, Laparoscopy, Laparotomy, Sigmoid Colon.

\section{Introduction}

Intra-uterine device (IUD) is one of the most common methods of contraception in the world but has been linked to several health risks. Uterine perforation is one of the most serious complications associated with IUD contraception. The incidence of uterine perforation has been reported between $0.05 \%$ and $0.13 \%$ or 1.3 to 1.6 per 1000 insertions $[1,2]$. We hereby report a woman with IUD translocation and perforation into the descending colon which was subsequently removed by laparoscopy and laparotomy.

\section{Case Report}

A 45-year-old woman, para 2, came to the hospital with intending to release an IUD because it had been implanted for 5 years. She had no significant medical history, and had no contraindications during her IUD implantation, 5 years back. Her IUD implantation was unremarkable and subsequent examination done after her next menstrual cycle had shown $2 \mathrm{~cm}$ long threads at the cervix. Her subsequent menstrual cycles and bleeding pattern were regular. IUD threads were reported as visible at subsequent follow-up visits.

Examination showed patient has a good general state, compos mentis awareness. During the vaginal speculum examination, the IUD tail was not found. Abdominal and pelvic ultrasound suggested an IUD is inside the uterine cavity. IUD evacuation was planned under anesthesia in the operating room. After exploration and evacuation, the IUD was not found inside the uterine cavity. Abdominal plain film radiograph, with uterine sondage examination found that the IUD had moved from the uterus into the pelvic cavity with a sonde not touching the IUD [Fig.1]. Laparoscopy failed to detect IUD inside the pelvic or abdominal cavity. Subsequent exploration on laparotomy found that the IUD was covered with omentum and the stem of the IUD penetrated descending sigmoid colon. IUD stem was wrapped in feces and had perforated colon and the intestine procedure was performed. The patient recovered well and was discharged from the hospital on the $7^{\text {th }}$ post-operative day. 


\section{Discussion}

Generally, modern IUDs are safe and effective. Translocation and perforation are rarely found in an IUD. Patients usually complain of lower abdominal pain, uterine bleeding or are asymptomatic like the case presented above. Many factors can cause this translocation, such as the position of the uterus that is not normal (hyper-anteversion and hyperretroversion), the stitching of the uterus that can cause weakness in the uterine wall and improper installation techniques [3]. Perforation is rare but is serious complication. Partial and total perforations occur usually due to incorrect installation of IUD, most possible mechanism being IUD migration if implantation done right after post-partum or during menstruation. Authors have previously reported removal of partially embedded IUDs in the sigmoid colon without any adverse consequences $[4,5]$. After the installation of the IUD, it is recommended to check the position of the IUD through the remaining thread. Remaining threads may break or be pulled back into the cervical canal or uterus and disappear or get shorter requiring further investigation. If threads are not located at usual location, imaging studies, such as ultrasound and X-rays, are essential to identify the location of the IUD [6]. In this case, a pelvic-sonde BNO $\mathrm{X}$-ray examination revealed IUD migrating from the uterus into the pelvic cavity with the sonde not touching the IUD. After translocation is suspected, exploratory surgery is the primary treatment that must be performed immediately [7].

\section{Conclusion}

The installation of an IUD needs more attention due to its potential to migrate out of the uterus in asymptomatic individuals and continue to cause complications such as intestinal perforation which can be fatal. This underlines the importance of routine examinations to find out the location of the IUD before it is too late with definitive therapy for surgical removal of the IUD.

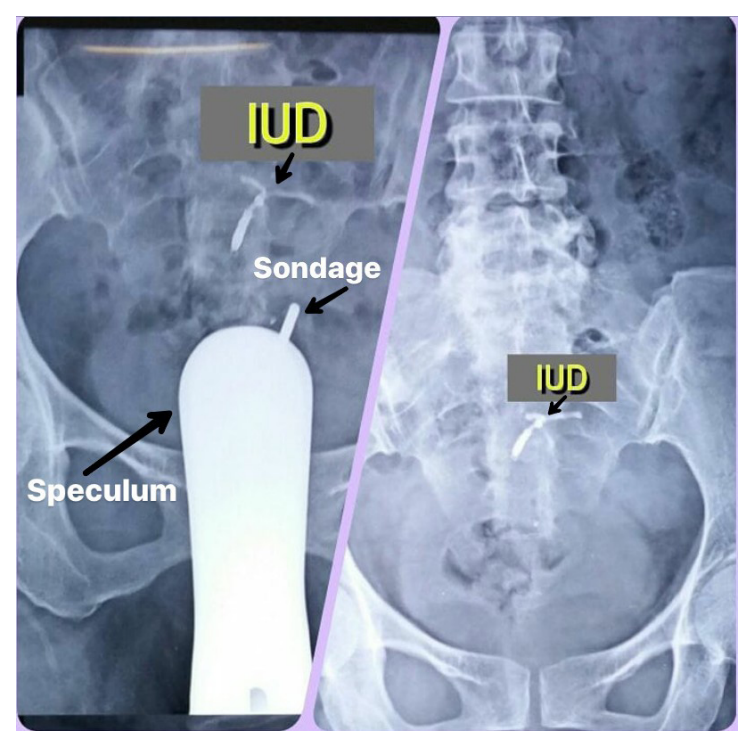

Fig.1: Abdominal plain film radiograph with uterine sondage examination, demonstrating the migrated intrauterine device.

Contributors: CP: manuscript writing and editing, patient management; GRY: manuscript writing; HIS: manusript writing. CP will act as a study guarantor. All authors approved the final version of this manuscript and are responsible for all aspects of the study.

Funding: None; Competing interests: None stated.

\section{References}

1. Arslan A, Kanat-Pektas M, Yesilyurt H. Colon penetration by a copper intrauterine device: a case report with literature review. Arch Gynecol Obstet. 2009;279:395-397.

2. Baakdah H, Asswad AF, Tulandi T. Sigmoid penetration by an intrauterine device. J Min Invasive Gyn. 2005; $12: 384$.

3. El-Hefnawy AS, El-Nahas AR, Osman Y, Bazeed MA. Urinary complications of migrated intrauterine contraceptive devices. Int Urogynecol J Pelvic Floor Dysfunct. 2008;19:241-245.

4. Gungor M, Sonmezer M, Atabekoglu C, Ortac F. Laparoscopic management of a translocated intrauterine device perforating the bowel. J Am Assoc Gynecol Laparosc. 2003;10:539-541.

5. Baakdah H, Asswad AF, Tulandi T. Sigmoid penetration by an intrauterine device. J Min Invasive Gyn. 2005; 12:384.

6. Braaten KP, Goldberg AP. Malpositioned IUDs: when you should intervene (and when you should not). OBG Management. 2012;24:38-46.

7. Mederos R, Humaran L, Minervini D. Surgical removal of an intrauterine device perforating the sigmoid colon: A case report. Int J Surg. 2008;6:60-62. 